\title{
Letters
}

\section{Reserve may be just another word for cowardice}

EDITOR-I was appointed as the second urologist in Plymouth at the age of 36 . When I was 38 I became ill, and Parkinson's disease was diagnosed.

I carried on working for nearly three years and kept my diagnosis a secret from everyone except my fellow urologist and some close friends, because I thought I would have no credibility as a surgeon if it were made public. Apart from thinking, somewhat altruistically, that I would be able to continue to be of some help to my patients, I also thought that as long as I was able to maintain my standards I did not need to give up. Over that time my weight dropped by over $13 \mathrm{~kg}$, and in the months leading up to making the diagnosis known I was told that various colleagues thought that I had diabetes, Huntington's chorea, motor neurone disease, multiple sclerosis, or AIDS or, in one case, that I was drunk.

Eventually, when the struggle to maintain my standards became too difficult and it was palpably obvious that something was wrong, I decided to give up. Despite all this not a single person came to ask me whether I had a problem. After I had announced the diagnosis (it gave me great satisfaction that no one got it right) I took a week off work to let things die down a bit.

My wife, who is a consultant in the same hospital, carried on working as usual and spent that week giving coffee and support to shocked friends and colleagues who were wondering how they were going to be able to cope with my diagnosis. Every evening she would tell me about the day's events-for example, what "so and so" had said and how "so and so" had burst into tears. It was like listening to a radio documentary about my own death. Somehow I felt rather left out, and I could have done with some show of emotion. I put it all down to the "Great English Reserve"-everyone knew but hardly anyone could bring themselves to say anything to me. On the Sunday before I was due to restart work I went in to the hospital to catch up with what was happening to my patients. As I walked towards the entrance one of my consultant colleagues was coming out and took a considerable detour to come up to me. When we stopped and met he asked, "How's the car going?" I think one can carry reserve a bit too far.

In reality I think it is cowardice. At a time like that any bit of support, whether verbal or written, is greatly appreciated. I agree that there is a great need for some sort of card that would allow people to show support and sympathy, ${ }^{1}$ but I think the necessity for such a card only arises because most people are afraid to show them face to face.

R G Choa Retired consultant urologist Nuffield Hospital, Plymouth PL6 8BG

1 Kapp, MB. New medical needs: the stay ill card. BMJ 1997; 315:1125. (1 November.)

**In her covering letter to this letter $\mathrm{Mr}$ Choa's wife wrote that "although he remains completely intellectually intact, this letter took him all day to type, which is a measure of how strongly he feels on these issues."EDITOR

\section{Intravascular volume optimisation during repair of proximal femoral fracture}

\section{Intravascular volume was depleted} perioperatively in control group

EDITOR-In their study investigating intravascular volume optimisation and proximal femoral fracture, Sinclair et al have a different approach to fluid replacement between the two groups studied. ${ }^{1}$ The control group received only a median volume of $1000 \mathrm{ml}$ of crystalloid (presumably Hartmann's or $0.9 \%$ saline solution) peroperatively. As only about a quarter of this solution is retained intravascularly, these patients effectively had a depleted intravascular volume perioperatively. In contrast, the protocol group received a median of $750 \mathrm{ml}$ of colloid as well as $725 \mathrm{ml}$ of crystalloid, giving intravascular fluid replacement of nearly 1 litre. The preoperative dextrosesaline maintenance fluids would have had minimal effect on the intravascular volume: only $15 \%$ of such a solution is retained within the intravascular compartment.

This study merely shows that patients who have not received fluid or who have fluid depletion have a higher rate of complications, which is not a surprising or new finding. A control group should be recognisable as such; if the control group has been deprived of fluid then this will magnify any benefits in the protocol group. We suggest that if adequate preoperative intravascular fluids, and not just dextrose-saline maintenance fluids, had been given to all patients, replacing the blood loss associated with femoral fractures (often in excess of 1 litre $^{2}$ ), then the differences between the groups would have been much less. A study comparing a group in whom optimisation is used with a group given sufficient fluid would be of much greater importance and would show the benefits of optimisation more clearly.

KW Toh Senior house officer in anaesthesia W J Fawcett Consultant anaesthetist Royal Surrey County Hospital Trust, Guildford, Surrey GU2 5XX

\section{Sinclair S, James S, Singer M. Intraoperative intravascular volume optimisation and length of hospital stay after repair of proximal femoral fracture: randomised con- trolled trial. BMJ 1997;315:909-12. (11 October.) \\ 2 Willet KM, Dorrell H, Kelly P. ABC of major trauma:} Management of limb injuries. BMJ 1990;301:229-33.

\section{Differences in outcome were probably due to chance}

Editor-Sinclair et al's randomised controlled trial of intraoperative intravascular volume optimisation in patients with proximal femoral fracture raises important issues regarding the preoperative administration of fluid to such patients and their operative care, ${ }^{1}$ particularly if it is taken in conjunction with a study by Schultz et al. ${ }^{2}$ Sinclair et al's study, in only 40 patients, suggested that optimisation of the intraoperative stroke volume resulted in a large reduction in hospital stay but not mortality. Schultz et al's study, in 70 patients, showed a reduction in mortality, from 10 of 35 patients in the control group to 1 of 35 patients in the group who had intensive physiological monitoring. Hospital stay was not reported on.

Results of both trials must be interpreted with more caution than that shown in the editorial by Gan and Arrowsmith. ${ }^{3}$ It is difficult to explain why each study produced profound changes in dissimilar outcome measures. Both studies were of small numbers of patients. Patients with hip fracture are a heterogeneous group, and multiple factors affect outcome. It is therefore unlikely that a change in one aspect of patient care would have such a large influence on the eventual outcome and much more plausible that the differences in outcome are due to chance.

A large number of observational studies have generally failed to suggest that isolated differences in anaesthetic methods, operative procedures, or preoperative care have significant effects on length of hospital stay or mortality. Gan and Arrowsmith's comment-based on only 40 cases-that routine use of oesophageal monitoring during surgery for hip fracture will save 450000 hospital bed days a year in Britain alone is misleading and unhelpful in the critical appraisal of an innovation. 
Undoubtedly we need further research, on a large number of patients in different clinical settings, to see if these potential benefits of new technology can be translated into real benefits. Until such studies are conducted, the role of intensive monitoring must be regarded as promising but unproved.

Martyn J Parker Orthopaedic research fellow Peterborough Hip Fracture Project, Peterborough Hospitals NHS Trust, Peterborough District

Hospital, Peterborough PE3 6DA

1 Sinclair S, James S, Singer M. Intraoperative intravascular volume optimisation and leng of hospital stay after volu stay after repair of proximal femoral fracture: randomise
trolled trial. BMJ 1997;315:909-12. (11 October.)

2 Schultz RJ, Whitfield GF, LaMura JJ, Raciti A, Krishnamurthy S. The role of physiologic monitoring in namurthy S. The role of physiologic monitoring in 3 Gan TJ, Arrowsmith JE. The oesophageal Doppler monitor: a safe means of monitoring the circulation. $B M$ 997;315:893-4

\section{Regional anaesthesia is usually technique of choice}

EDITOR-We wish to make several comments about Sinclair et al's randomised controlled trial on intraoperative intravascular volume optimisation and length of hospital stay after repair of proximal femoral fracture. ${ }^{1}$

Firstly, regional anaesthesia is generally accepted to be the technique of choice in most patients with traumatic fractures of the neck of femur, because of improved outcome in general and a reduced incidence of postoperative thrombotic complications in particular. ${ }^{2}$ Sinclair et al, however, specifically excluded patients for whom regional anaesthesia was planned because use of this technique would preclude the placement of an oesophageal probe. Surely this fact minimises the impact of their findings, as patients having general anaesthesia for repair of proximal femoral fracture are a relatively small subgroup of this population.

Secondly, the only haemodynamic data provided by the authors are stroke volume, cardiac output, and aortic flow time. While cardiac output is one of the main factors influencing mean arterial blood pressure and hence organ perfusion, the other main factor contributing to mean arterial pressure-systemic vascular resistance-is not reported. The potential beneficial effect of increased cardiac output on organ perfusion may be negated by large reductions in systemic vascular resistance.

Sinclair et al's findings of improved cardiac output when colloid was given to patients under general anaesthesia conflict with studies in patients undergoing spinal anaesthesia, in which cardiac output was measured non-invasively by transthoracic bioimpedance. In one such study, prehydration with gelatin colloid did not prevent the reduction in blood pressure induced by spinal anaesthesia in normovolaemic elderly patients, whereas an infusion of the $\alpha$-adrenergic agonist metaraminol did. ${ }^{3}$

Our study comparing prehydration with gelatin colloid, prehydration with crystalloid, and no prehydration found no benefit, in terms of haemodynamic stability, with either fluid regimen over none. ${ }^{4}$ In a further investigation, hetastarch $6 \%$ given in combination with crystalloid was also found to be ineffective compared with intramuscular methoxamine (another $\alpha$-adrenergic agonist) in an elderly population with fractures of the femoral neck. ${ }^{5}$ In neither of these studies, however, did we undertake the postoperative follow up of outcomes conducted by Sinclair et al.

Further studies, in which similar postoperative outcome measures are used as end points, are needed in patients undergoing spinal anaesthesia, who constitute the overwhelming majority having this surgery. Such studies must determine whether similar benefits may be obtained by close control of cardiac output and other haemodynamic variables, especially systemic vascular resistance, by using supplementary colloids or vasopressors.

Donal Buggy Senior registrar

Gerard Fitzpatrick Consultant anaesthetist

Department of Anaesthesia, Meath Hospital,

Dublin 8, Republic of Ireland

1 Sinclair S, James S, Singer M. Intraoperative intravascular volume optimistion and length of hospital stay after volume optimisation stay after relle of proxi Modig J, Borg I, Bagge L, Saldeen T. Role of epidural an general anaesthesia in fibrinolysis and coagulation c

3 Critchley L, Conway F. Hypotension during subarachnoid anaesthesia: haemodynamic effects of colloid and metaraminol. Br J Anaesth 1996;76:734-6.

Buggy D, Higgins P, Moran C, O'Brien D, O'Donovan F, McCarroll M. Prevention of spinal anesthesia-induce hypotension in the elderly: comparison between preanesthetic administration of crystalloid, colloid and no prehydration. Anesth Analg 1997;84:106-10.

5 Buggy DJ, Power CK, Meeke R, O'Callaghan S, Moran C, O'Brien R. Prevention of spinal anesthesia-induced hypotension in the elderly: intramuscular methoxamine or prehydration with 6\% hetastarch and crystalloid combined. Br J Anaesth 1998;80:199-202.

\section{Authors' reply}

Editor-We agree with Toh and Fawcett that our control patients were underresuscitated and fluid deplete. In our patients, initial resuscitation, which included blood, was conducted as clinically appropriate. All patients then received preoperative crystalloid during the period of obligatory starvation, a practice that is not common in many hospitals. Furthermore, by a Hawthorn effect, more attention would probably have been paid to peroperative circulatory status in our control patients.

We would argue that optimisation is impossible without flow monitoring. To answer Parker, is it not ironic that the two interventional studies that monitored and acted on flow data (ours and that by Schultz et $\mathrm{al}^{1}$ ) have been the only studies that have shown significant outcome benefit in surgery for hip fracture? Of course, this could be due to chance. The large number of observational studies that Parker mentioned have failed to consider the impact of adequate fluid resuscitation. We hope that our study has highlighted this neglected area.

Parker is unfair to criticise Gan and Arrowsmith's editorial, which stated the potential gain through flow monitoring but argued for large scale confirmatory studies before its routine introduction.

We and others ${ }^{2}$ would dispute Buggy and Fitzpatrick's claim that regional anaes- thesia is the technique of choice in surgery for hip fracture. A meta-analysis has not shown improved outcome. ${ }^{2}$ Their quoted reference from a 1983 paper concerns total hip replacement, not traumatic fracture. Surgery for hip fracture under general anaesthesia may be relatively uncommon in their hospital but is unsubstantiated by any general data. In the 1993-4 national confidential enquiry into perioperative deaths, ${ }^{3} 23 \%$ of the deaths followed surgery for hip fracture and only a minority of the patients received regional anaesthesia alone. We are confused by their interpretation of physiology. A large reduction in systemic vascular resistance is relevant only if blood pressure and organ perfusion pressure drop below a critical level. At the end of a sprint a runner's systemic vascular resistance will be $40 \%$ of normal but he or she does not generally require vasoconstrictors. Heart rate and blood pressure did not change significantly in either group in our study.

Finally, the use of vasopressors in elderly patients is not without danger. Flow may be severely compromised, especially with $\mathrm{CO}^{-}$ existing hypovolaemia. Flow monitoring is necessary both to confirm benefit and to exclude harm in individual patients. We would encourage the authors to perform outcome studies to determine whether the subset of patients with compromised flow after administration of an $\alpha$ agonist develop complications in the postoperative period.

Mervyn Singer Senior lecturer in intensive care medicine

University College London Medical School, London WC1E 6JJ

Sue Sinclair Anaesthetic specialist registrar Whipps Cross Hospital, London E11 1NR

1 Schultz RJ, Whitfield GF, LaMura JJ, Raciti A, Krishnamuthy $\mathrm{S}$. The role of physiologic monitoring in patient with fractures of the hip.J Trauma 1985;25:309-16.

2 Sorenson RM, Pace NL. Anesthetic techniques during surgorenson RM, Pace NL. Anesthetic techniques during sur-
gical repair of femoral neck fractures. A meta-analysis. gical repair of femoral neck fiac

Anesthesiology 1992;77:1095-104. Report of the national confidential enquiry into perioperation
deaths (NCEPOD) 1993/1994.London: NCFPOD, 1996.

\section{Oral contraception was not associated with venous thromboembolic disease in recent study}

EDITOR-Three studies published in 1995-6 reported odds ratios for venous thromboembolic disease among women using third generation oral contraceptives compared with women using second generation products that were in the range 1.5 to $1.8 .^{1-3}$ The design limitations and interpretation of the results of these studies have been widely questioned. A further study, based on computer records from 147 general practitioners in Britain, failed to show any significant difference in the risk of venous thromboembolic disease between generations of oral contraceptive.

To investigate the issue further we analysed data from the German MediPlus database (October 1992 to September 1995), which is similar in principle to the 
Use of oral contraceptives by cases and controls. Figures are numbers of women

\begin{tabular}{lcc} 
Type of contraceptive & Cases & Controls \\
\hline Second generation & 27 & 89 \\
\hline Third generation & 15 & 64 \\
\hline Others & 0 & 15 \\
\hline Total & 42 & 168 \\
\hline
\end{tabular}

British MediPlus database, and the General Practice Research Database. Cases were 42 women aged 18-49 with venous thromboembolic disease who were exposed to an oral contraceptive at the time and were treated with an anticoagulant. We randomly selected four controls per case (168), matched by year of birth and exposure to an oral contraceptive on the event day.

For each woman we extracted the history of use of oral contraceptives, recent medical history, and consultations for physical or psychotherapeutic complaints between January 1992 and the event day. Records of body mass index (or weight), blood pressure, or smoking habit were insufficient to warrant the inclusion of these variables as possible confounders.

More women used second than third generation pills, and none used progestogen only pills (table). We found no significant difference between cases and controls in the type of oral contraceptive used on the event day (unadjusted odds ratio for users of third compared with second generation pills was 0.77 (95\% confidence interval 0.38 to 1.57$)$ ); this is consistent with the results of the British MediPlus study. ${ }^{4}$

In both the cases and controls there was no significant difference in age between users of second and third generation pills. There was also no significant difference in the number of prescriptions for oral contraceptives (means 0.29 and 0.27 ), consultations for psychotherapeutic complaints alone (means 0.29 and 0.27 ), or mixed psychotherapeuticphysical consultations (means 0.26 and 0.11 ). The cases did, however, have significantly more consultations than the controls for purely physical reasons before the event (means 13.57 and 5.44; $\mathrm{P}<0.0001$ ). This difference might indicate poorer health status or prodromal symptoms in the cases or unequal diagnostic surveillance of cases compared with controls, with diagnoses being more likely in frequent attenders. This area, although requiring further investigation, was not related to the type of progestogen in the oral contraceptive used.

R D T Farmer Professor

J-C Todd Research assistant

K D MacRae Reader

TJ Williams Research assistant

Department of Public Health, Imperial College

School of Medicine (University of London),

London SW10 9NH

M A Lewis Director

Epidemiology Pharmacology and Systems

Research, Berlin, Germany

1 WHO Collaborative Study of Cardiovascular Disease and Steroid Hormone Contraception. Effect of different progestogens in low oestrogen oral contraceptives on venous thormboembolic disease. Lancet 1995:346:1582-8 2 Spitzer WO, Lewis MA, Heinemann LAJ, Thorogood M, MacRae KD. Third generation oral contraceptives and risk MacRae KD. Third generation oral contraceptives and risk of venous thromboembolic disorders: case-control study. BMJ 1996;312:83-8.
3 Jick H, Jick SS, Gurewich V, Myers MW, Vasilakis C. Risk of idiopathic cardiovascular death among non-fatal venou thromboembolism in women using oral contraceptive with differing progestogen components. Lancet 1995 $346: 1589-93$

4 Farmer RDT, Lawrenson RA, Thompson CR, Kennedy JG, Hambleton IR. Population-based study of risk of venou thromboembolism associated with various oral contraceptives. Lancet 1997;349:83-8.

\section{Working in management}

NHS managers have fundamental duty to put patients first

EDITOR-Many doctors find that solving management problems appeals to their creative talents. Some have found the experience so rewarding that they wish to continue. For others it is an emotionally draining, and at times nerve wracking, experience. This, it seems, is what Ayres has found, for he has emerged with a truly fanciful notion of the role of the manager. ${ }^{1}$

The quality of the product of health care is determined by the expert skills and knowledge of the front line workers-the clinicians-who, by every decision they make, commit whatever resources are available. The non-clinical managers cannot directly control their activity. Yet they are in place to take responsibility not only for effective use of resources but also for implementing all other aspects of government health policy. This demands a skilled, sensitive management team, drawing on the skills and leadership qualities of the medical and nursing staff and pulling the decentralised clinical teams together to form an effective, corporate whole.

Ayres concedes that operational management staff will always be needed in the NHS Healthcare provision, however, demands an extremely high calibre of leadership, in addition to "operational management." It is difficult, but essential, to devolve power, authority, and budgetary responsibility while at the same time delivering health objectives such as improved health status, equity, equality of access, and quality standards.

In one respect though, Ayres and I are of one mind. It seems to me that NHS managers, as well as all NHS staff, have a fundamental duty to put patients first. Tensions between professionals and managers are inevitable. Misunderstanding of each other's role and conditions of work removes the likelihood of responsible and informed management decisions. The public, to whom we are accountable, demands and deserves top managerial skills to lead and develop its most valued institution.

Yet, says Ayres, the NHS is "already cheap and efficient" and if the other $94 \%$ of gross domestic product was as well spent we would be leading Europe on education and public health services as well as on health. What an accolade for the achievements of general management in the NHS. Many thanks.

Dianne M Jeffrey Chairman

Community Health Care Service North Derbyshire NHS Trust, Chesterfield S41 7PL

1 Ayres R. A year in management. BMJ 1997;315:957-8. (11 October.)

\section{Doctors do better financially than} managers do

EDITOR-It is unfortunate that Ayres learnt so little in his attached year in management. ${ }^{1}$ Pejorative comment and stereotyping are no substitute for reasoned discussion. Some managers, it is true, earn $£ 55000$ a year or more, but most don't. An appointment at a grade that is generally only one step below board level pays about $£ 32000$, or the same as that paid to a second year senior house officer on 20 additional duty hours with as little as three years' experience. All consultants earn $£ 55000$ but most much more, as do most general practitioners. Trust chairmen are limited to a stipend of $£ 20000-$ no extra fees, court work, private work, and so on. Most of the doctors I know have sharp suits and mobile phones and drive aboveaverage cars. Perpetuating the stigmatic view of managers as "fat cats" is both pointless and hypocritical.

Ayres is right that public health is important and that the internal market is nonsense. Neither of these was caused or wished for by NHS managers, who on the whole agree with him; they were caused by political dogma and a medical profession that had no new ideas other than to spend more money. How does he think things can be changed other than by high level operational and strategic management, led by clinicians supported by high quality managers?

Finally, though the NHS is efficient, the idea that no wasteful clinical activity remains is hopelessly naive. Every issue of the $B M J$ contains examples. Incidentally, management costs in the NHS have been falling consistently for several years and are among the lowest in any developed healthcare system. Ayres should go back and try again, with a more open mind. Managers, clinicians, and patients share the same objectives. Working together, instead of abusing one another, we might stand a better chance of achieving them.

Stephen Hunter Medical director Gwent Community NHS Trust, Cwmbran, Gwent NP44 8YN

1 Ayres R. A year in management. BMJ 1997;315:957-8. (11 October.)

\section{Having public health doctors as managers is not the solution}

Editor-Ayres makes a heartfelt plea for changes in the management in the NHS. ${ }^{1}$ His personal view contains several statements that many doctors will at first readily identify with, but they merit closer attention.

He implies strongly that all managers of secondary care services, besides those involved in menial administrative tasks, should be medically trained. There are a few problems with this. Where are these would-be medically trained managers? Are enough doctors willing to give up what they have been trained in to do something they haven't been trained in? The author himself lasted but one year. More importantly, why should someone who is medically trained 
automatically be a better manager than someone who is managerially trained? General practitioners and primary care teams almost invariably appoint as a practice manager a person who is not medically trained; why should secondary medical care be any different? Surely the best people to manage health services are the best managers.

To a degree the author tries to circumvent this by urging public health doctors to take up the task. Again, several problems arise. There simply aren't enough public health doctors to do this while there are just 600 consultant posts nationally, and recruitment is being reduced. Even if there were enough public health doctors. why should they wish to restrict themselves to managing healthcare services? Public health is about much, much more than healthcare services, and public health trainees learn that quickly. With the recent appointment of a minister for public health we in public health are looking forward to increasing our joint working with the many agencies outside health services in order to improve the public's health. To me, the thought of being restricted to managing healthcare services-whose impact on health, though important, is restricted-fills me not with enthusiasm but with dread.

Tom Scanlon Medical adviser

East Sussex, Brighton and Hove Health Authority, Lewes, East Sussex BN7 2PB

Avres R. A year in management. BMJ 1997;315:957-8. (11 October.)

\section{New method of expressing survival in cancer is popular}

EDITOR-We are delighted that our method of calculating the "normal remaining life" to express survival in cancer aroused so much interest, and we would like to respond to some of the issues raised in letters. ${ }^{1}$ Tan suggests that the life expectancy figures that we used represent the median survival for a population cohort. ${ }^{2}$ This is untrue. We used cumulative yearly probability of death to calculate our figures of life expectancy, which is the age at which the probability of death reaches $100 \%$. The median survival, on the other hand, is the age at which the probability of death reaches $50 \%$. When we say that a woman aged 40 has a life expectancy of 75 we mean that the cumulative probability of her dying by age 75 is $100 \%$, not $50 \%$ (median survival) as Tan assumes.

There were several suggestions that living one's full normal remaining life does not equate with cure, because cure is thought to mean complete biological elimination of disease. We thought that a patient would really be interested in a personal cure, meaning that she will not die of the disease before she has lived her full normal life span. To keep things simple, we used only mortality data in our paper; inclusion of data on relapse would give an estimate of the chance of living the full normal life span without the disease relapsing.
Finally, what has given us the most satisfaction is that our method appealed to a patient with breast cancer, Harrison. Patients like her-a doctor herself-are the real reason for our paper, especially because she laments the fact that her prognosis was not calculated on the basis of our method when she developed cancer. Her feelings are being echoed in an ongoing study of patients' preferences about communication of the prognosis that we are conducting.

Jayant S Vaidya Surgical research fellow Department of Surgery, Institute of Surgical Studies, University College London, London W1P 7LD

Indraneel Mittra Consultant surgeon

Department of Surgery, Tata Memorial Hospital, Parel, Bombay 400 012, India

1 Vaidya JS, Mittra I. Fraction of normal remaining life span: a new method for expressing survival in cancer. $B M$ 1997;314:1682-4. (7 June.)

2 New method for expressing survival in cancer [letters] BMJ 1997;315:1375-6. (22 November.)

\section{Drug and Therapeutics Bulletin defends its stance over donepezil}

EDITOR-Wilkinson et al criticise a review of donepezil published in Drug and Therapeutics Bulletin and question the basis for our conclusion. ${ }^{12}$ The position we took was the result of much deliberation, in accordance with our normal practice. ${ }^{3}$ A detailed review of the literature makes up a large part of the preparation of articles in Drug and Therapeutics Bulletin. ${ }^{3}$ Ultimately, conclusions are based on our interpretation of such data, coupled with the views of our 40 or so consultants. Our goal is to produce a weighted assessment, and in this process a hierarchy of value is given to our source materials. Well controlled clinical trials or overviews published in full in peer reviewed journals are given most credibility; abstracts and data on file have little or no influence. Pfizer offered us sight of the report on donepezil-then unpublished in Neurology ${ }^{4}$-but because the restrictions that the company placed on us were so constraining we were unable to accept. Pfizer did, however, provide us with a synopsis. Selective (or constrained) quotations must be interpreted with caution.

We believe that the position taken in our review was reasonable and, moreover, would probably have been reached by prescribers in the United Kingdom generally if they had also analysed the published data available. Clearly, interpretation can alter, and we made it clear that our "position would change if more tangible evidence became available showing that the product offers real improvement in patients' wellbeing." In accordance with this, we plan to publish a review of the recent paper by Rogers et al. ${ }^{4}$ At present, we still have no reason to change our original conclusion. In our opinion, it is the assertion by Wilkinson et al that our position was "idiosyncratic or uninformed" that needs to be substantiated. We note that Wilkinson et al did not challenge our view that "it is not acceptable to ask doctors to make decisions on the basis of the results of a single, clinically inconclusive trial." We assume that they too found the findings in the original trial unconvincing. ${ }^{5}$ Finally, Wilkinson et al suggest that we should have reviewed the material on donepezil submitted to various licensing authorities. Such material is confidential and inaccessible.

Joe Collier Editor, Drug and Therapeutics Bulletin Consumers' Association, London NW1 4DF

1 Wilkinson D and 17 others. Advertisements for donepezil. BMJ 1997;315:1625. (13 December.)

2 Donepezil for Alzheimer's disease. Drug Ther Bull 1997;35:75-6.

3 How Drug and Therapeutics Bulletin produces articles. Drug Ther Bull 1997;35:73-4.

4 Rogers SL, Farlow MR, Doodv RS, Mohs R, Friedhoff LT. A 24-week, double blind, placebo-controlled trial of donepezil in patients with Alzheimer's disease. Nourology pezil in patients

. The Sficact The efficacy and safety of donepezil in patients with Alheiniz's disease. Resuls of a US multi centre, Dandomized, double-blind Dementia 1996; 7:293-303.

\section{Rationing health care}

\section{Patients need to be prioritised}

EDITOR-In his editorial on rationing health care Weale refers to an "inconsistent triad." $\mathrm{He}$ argues that it is a contradiction to propose that a healthcare service can be fully comprehensive, of high quality, and freely available to all within a finite resource allocation, although any two of these ideals may be achieved at the expense of the third.

In the NHS all three ideals are, theoretically, supported, although in practice none are supported fully. The range and quality of treatments offered are limited by a lack of equipment, training, and support. In addition, long waiting lists are a haphazard means of excluding patients from access to treatment; for various reasons some patients "drop out" and never reach the point of receiving NHS treatment. In our opinion, a random, disorganised, and covert form of rationing is therefore currently taking place in the NHS.

We believe that access to a comprehensive range of high quality treatment is essential and that if anything is to be "sacrificed" it must be access to treatment. From a clinical perspective, if patients can benefit from a treatment then there is no medical reason to withhold it. When consideration is being given to limiting access to treatment on the grounds of resources or costs, the decision cannot be made ethically on the basis of the treatment profile or the pathology but must be based on an individual person's level of need.

We are trying to develop a rational and effective system of prioritising patients by scoring the level of need of individual patients. Linking the resource requirements to the cases then allows a calculation of which cases can be treated with the allocated resources. If the available resources are insufficient to meet a minimum acceptable level of need then the only ethical answer is to increase the available resources. 
If such prioritisation can be made to work then the conversion of the current "rationing" from covert to overt may provoke a realistic reappraisal of the true costs involved (money versus suffering). This may lead to a more informed decision about what we as a nation could and should afford.

Brian Davis Consultant ear, nose, and throat surgeon Steve Johnson Consultant orthopaedic surgeon Carmarthen and District NHS Trust, West Wales General Hospital, Carmarthen SA31 2AF

Weale A. Rationing health care. BMJ 1998;316:410 (7 February.)

\section{Debate is needed about core range of health services that will be available}

EDITOR-In his editorial on the current debate about healthcare costs and organisation, Weale calls for honesty about the lack of comprehensiveness and the definition of a core range of health services. ${ }^{1}$ This approach is timely, given decisions to be taken soon about the resources to be allocated to many new primary care groups and the creation of the health improvement programmes by health authorities and boards. Both these initiatives, arising from the white paper The New $N H S^{2}$ and due to start in April next year, may well intensify the debate to which Weale refers.

In the recent green paper Our Healthier Nation it is envisaged that health improvement programmes will "set out a range of locally-determined priorities" and "show that action proposed [to address these] is based on evidence of what is known to work." ${ }^{3}$ Though I welcome the latter action, is it not likely that the potentially wide range of locally determined and national priorities agreed across the nation may further broaden the "core range of services" and stretch the resource allocation process even more to breaking point? The likely size and number of the emerging primary care groups will become clearer in the coming weeks. Health authorities and boards will, however, face a particularly challenging task in both addressing and reducing health inequalities (as, rightly, proposed in Our Healthier Nation) and ensuring that their primary care groups receive sufficient resources so that even a core range of health services can be purchased.

Further and urgent debate is needed about this core range of health services which will be available nationally-if for no other reason than to help protect the emerging primary care groups from being the scapegoats in the rationing debate. Won't they have enough other things to do?

G Worth Director of public health

Calderdale and Kirklees Health Authority,

Huddersfield, West Yorkshire GD4 5RH

1 Weale A. Rationing health care. BMJ 1998;316:410. (7 February.)

2 Secretary of State for Health. The new NHS. London: HMSO, 1997.

3 Secretary of State for Health. Our healthier nation. London: HMSO, 1998.

\section{Breast feeding does not always work}

\section{Author should have felt angry rather than guilty}

Editor-Bennison's Personal View gives the impression that she has been left with some sense of guilt after she was unable to exclusively breastfeed her baby. ${ }^{1}$ Maybe she should be feeling angry rather than guilty, because support and informed advice do not seem to have been available when she needed them.

The actual reasons for Bennison's lack of success are not clear from the article, and it is perhaps presumptuous of us to propose possible retrospective solutions. Her difficulties may have been due to insurmountable problems related to low birth weight and prematurity. On the other hand, some of her difficulties may have been quite solvable. The mention of "frequent brief feeds" suggests that the baby did not have the opportunity to get enough milk, especially hindmilk, and therefore it was not surprising that the infant was "starving." This may have been the result of poor positioning, which is the most common problem for breast feeding mothers and a prime cause of lactational failure.

When Jenny needed help the "paraphernalia of bottle feeding" was not what was required. Instead it might have been more helpful to have a person experienced in dealing with breast feeding problems who could advise about how to manage breast feeding so that the baby got complete and nourishing feeds. In countries where infants rely on breast milk this kind of community support ensures that death rarely, if ever, results from mechanical failure. In Bennison's case it was not her failure but the failure of our community to support breast feeding fully.

Janet Mair General practitioner

Cara Flanagan General practitioner

Kyle of Sutherland Breastfeeding Initiative, Creich Surgery, Bonar Bridge, Sutherland IV24 3ER

1 Bennison J. Breast feeding does not always work. $B M$ 1997;315:754. (20 September.)

\section{All mothers should be offered help and support to breast feed}

EDITOR-As a health professional who has recently had a baby, I can identify with Bennison's feelings about her problems with breast feeding her daughter. ${ }^{1}$ It is often assumed that health professionals know everything about various aspects of health, pregnancy, and child care and that the practical skills will come along with this vast amount of assumed knowledge. This can lead to assumptions by healthcare staff that the mother knows what she is doing, and thus little help and support is offered. Health professionals, unsure of their own knowledge, may be frightened to give advice because the mother may have superior knowledge.
The Baby Friendly Hospital initiative should help to prevent occurrences such as this. Staff will be given the knowledge and training needed to support breast feeding mothers and will have the back up offered by policies, research, and other appropriately trained staff. At present, however, this initiative is in its infancy, and policies are sometimes implemented without thought for individual circumstances. For instance, bed sharing-a good idea-has become so popular that mothers are sometimes encouraged to bed share even if they are taking drugs such as morphine. In the same way, demand feeding is now encouraged for healthy term infants. In Bennison's case, where the infant seemed fairly small, perhaps three hourly feeding might have been more appropriate, but without full details it is difficult to comment. Individual circumstances must, however, be considered and the advice tailored appropriately.

We currently lack a breast feeding culture; therefore all mothers should be offered help and support to breast feed regardless of their background and previous experience. Until we are skilled in supporting breast feeding mothers, the number of women who are unable to breast feed will remain unknown. The proportion of these women may be small; they and other mothers who make an informed choice to bottle feed should be encouraged and supported in the feeding manner of their choice.

Finally, health professionals with newborn babies should be given even more information and support than other mothers because they will probably return to their career. Their personal experience is thus likely to affect the care and advice that they give to others for years to come.

Rhona J McInnes Research midwife Paediatric Epidemiology and Community Health (PEACH) Unit, Department of Child Health, Yorkhill NHS Trust Hospital, Glasgow G3 8SJ

1 Bennison J. Breast feeding does not always work. BMJ 1997;315:754. (20 September)

\section{Various supplements to breast feeding} are possible

EDITOR-Successful breast feeding is not a matter of luck, as Bennison seems to suggest. ${ }^{1}$ Excessive weight loss and dehydration in an otherwise well baby suggest not that breast feeding does not work but that its management has been faulty. Increasing jaundice and failure to pass stools in a well newborn baby strongly suggest inadequate intake. Possible causes include drugs used in labour which affect feeding behaviour, infrequent breast feeding leading to the slow establishment of lactation, and incorrect positioning of the baby at the breast (almost certainly the case if the mother is experiencing "the agonies of engorgement and cracked nipples")

The effectiveness of the transfer of breast milk needs to be evaluated repeatedly by experts in the early days; problems of technique should be corrected. If feeding at the breast is genuinely inadequate then the 
baby must be given supplements in a manner that will allow the eventual establishment of full breast feeding. Supplements to breast feeding are, in order of preference, expressed maternal milk, donated human milk, and formula. The use of a non-bottle feeding method, such as cup feeding, may be associated with a higher incidence of maintenance of breast feeding than is bottle feeding. ${ }^{2}$ Well down the list of options is formula given by bottle; this seems to have been the only possibility offered to Bennison. The need for intravenous rehydration should probably never arise in a well baby, but if it does the baby can be put back to the breast and, with skilled help, lactation can eventually be established.

Considerably more mothers in Britain started to breast feed in 1995 than in 1990, but nearly half of them had abandoned breast feeding by six weeks. The commonest reasons given for stopping early were nipple and breast pain and inadequate milk supply, ${ }^{3}$ which are almost always preventable or manageable problems. This suggests a lack of expertise among health professionals. Unfortunately, many medical textbooks give inadequate or misleading information on breast feeding. An information resource for doctors is available at http://www.btinternet.com/ fulton/medlact.htm.

In the same issue of the $B M J$ Butland et al suggest that breast feeding does not protect children from hay fever and eczema. ${ }^{4}$ They obtained information on the duration of breast feeding seven or five years after the event but give no data on the exclusiveness of breast feeding. They thus add to six decades of research into atopy and breast feeding, which is invalidated by faulty experimental method.

C M A Campbell Clinical medical officer

Foyle Health and Social Services Trust, Community Paediatric Department, Londonderry BT47 1TG ccampbell@btinternet.com

1 Bennison J. Breast feeding does not always work. $B M J$ 1997;315:754. (20 September.)

2 Lang S, Lawrence CJ, Orme RL'E. Cup feeding: an alternative method of infant feeding. Arch Dis Child 1994;71:365-9.

3 Office for National Statistics. Breastfeeding in the United Kingdom in 1995. London: ONS, 1997

4 Butland BK, Strachan DP, Lewis S, Bynner J, Butler N, Britton J. Investigation into the increase in hay fever Britton J. Investigation into the increase in hay fever 1970 British birth cohorts. BMJ 1997;315:717-21. 1970 British

5 Kramer MS. Does breast feeding help protect against atopic disease? Biology, methodology, and a golden jubilee atopic disease? Biology, methodology, and
of controversy. J Pediatr 1988;112:181-90.

\section{Bottle feeding may help babies develop sucking skills}

EDITOR-Bennison's experiences of breast feeding are not unusual. ${ }^{1}$ Our son also refused to heed the advice of the midwives and could not acquire the necessary skills for breast feeding. It took us a little while to realise that his irritability at night was simply because he was starving.

My wife experienced tremendous feelings of guilt when the bottle was introduced and her ravenous son downed the lot. As he developed the necessary sucking skills, how- ever, he found that he could use them to get milk from the breast as well. We soon had a baby who could switch from breast to bottle and back without any problem.

We need to avoid inducing guilt in mothers who, despite all efforts, cannot get breast feeding to work. In addition we must keep our minds open to all possibilities and not simply say that, once on the bottle, that is it. In fact, it could solve the problem.

Richard Vautrey General practitioner

Meanwood Group Practice, Leeds LS6 4JN

1 Bennison J. Breast feeding does not always work. $B M$ 1997;315:754. (20 September)

Women need support as they decide what is best for them

EDITOR-In his review of the book The Lost Art of Healing, Weatherall emphasises the need to listen to each individual's story as a vital part of the healing process. ${ }^{1}$ On the facing page and in the next week's issue of the $B M J$ are the stories of two women and their new babies, centred on their experiences of breast feeding. ${ }^{2}{ }^{3}$ Nelson describes the illumination of personal experience over detached research. ${ }^{3}$ Bennison's frightening first week with her daughter exemplifies the harm that can be done when the individual is lost sight of in the drive to establish behaviour for a population's benefit. ${ }^{2}$

Surveys of breast feeding consistently show high discontinuation rates in women who were motivated enough to start. Why? These women must be listened to by advocates of breast feeding if these figures are to be understood and improved on. Equally valid are the stories of women who opt to give formula feed from the outset. Each mother and baby deserves to be viewed as a unit, and reassurance is needed that what is best for a mother will inevitably be best for her child. These needs will depend on the unique situation of each mother and child and their family and cannot always be extrapolated from population based statistics. The priorities of a Bangladeshi and a British family may be quite different. The Bangladeshi family may have a dirty water supply, but the British family, often materially secure, can have other anxieties: not least of these is the insidious pressure for the mother to be a "super mum." This leaves her feeling a failure if she does not have a spontaneous vaginal delivery with minimal analgesia and does not breast feed her baby for a long time.

"Breast is Best" campaigns are well intentioned but create a second class of mothers who choose or are forced to give formula feed. To feel within weeks of your baby's birth that you have given him or her second rate nutrition does nothing for one's self confidence, which is often already low. We need to shift from the potential for health fascism in campaigns to a family centred approach. This means supporting women as they decide what is best for them. A more relaxed and collaborative relationship could produce innovative ways of over- coming difficulties with breast feeding and make breast feeding more attractive but also support decisions to give formula feed. This will take less dogma and more listening, but what better time to start than with each new life?

Laura Jones General practitioner

14a Verran Place, Christchurch, New Zealand

1 Weatherall DJ. The lost art of healing [book review]. BMJ 1997:315:755. (20 September)

2 Bennison J. Breast feeding does not always work. BMJ 1997;315:754. (20 September.)

3 Nelson J. Ban the bottle. BMJ 1997;315:822. (27 September.)

* We received six other letters discussing problems of breast feeding.-EDITOR

\section{Human Fertility and Embryology Act 1990 discriminates against children}

\section{Children must not be denied future choice of using their gametes}

EDITOR-Childhood cancer affects 1 in 600 children. Five year survival rates now exceed $65 \%$, which means that by the beginning of the next millennium 1 in 950 young people aged 16-35 will have been cured of cancer. ${ }^{1}$ Unfortunately, many of the treatments used may sterilise some of these young people. ${ }^{2}$

Rapid developments in fertility treatment result in new solutions that we, as paediatricians, need to exploit in order to offer our young patients the best opportunities. ${ }^{3}$ The current legal framework for harvesting, storing, studying, and using human gametes is defined by the Human Fertilisation and Embryology Act 1990. Paragraph 3.38 of this code of practice states that valid consent must be obtained from those aged under 18 before their gametes may be harvested. When the Human Fertilisation and Embryology Authority was asked for clarification, its view was that "although parental consent may be obtained for a child's examination and treatment, the parents cannot consent on their child's behalf to the use and storage of their child's gametes."

We believe that this discriminates against those children who are unable to give informed consent and that it is in contrast to our daily practice, where consent for clinical procedures in children is sought and obtained from parents and from the children themselves. Many established forms of treatment in paediatrics are associated with risks of substantial morbidity and, on occasion, death, and parental informed consent is both ethically and legally acceptable.

The option of seeking approval for individual cases through judicial review or application to the fertilisation authority exists, but we think that this is cumbersome. Expecting a family to jump through a series of legal hoops at a time when it may be coming to terms with a new diagnosis of cancer is cruel and unnecessary. 
If we are to offer young people the possibility of being fertile after they have successfully overcome their cancer, we must at least permit the parents to consent on their behalf to obtain and store the necessary gametes, and to undertake research on them. We recognise that only the patient donating gametes should give consent to their use at a later date and that this consent would be given at a time in life when the patient had a full and informed understanding of its implications. As children's specialists, however, we cannot deny our patients that future choice simply because they are too young to understand.

Martin Hewitt Consultant paediatric oncologist David Walker Senior lecturer in paediatric oncology Department of Child Health, Queen's Medical Centre, Nottingham NG7 2UH

Michael Sokal Consultant oncologist

Department of Clinical Oncology, City Hospital,

Nottingham NG5 1PB

1 Stiller CA. Population based survival rates for childhood cancer in Britain. BMJ 1994;309:1612-6.

2 Blatt J Copeland DR, Bleyer WA Late effects of childhood

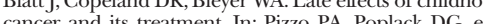
Principles and practice of $p$ Principles and practice of pediatric oncology. Philadelphia Lippincott-Raven, 1997:1303-30.

3 Fishel S, Green S, Hunter A, Lisi F, Rinaldi L, Lisi R, et al. Human fertilisation with round and elongated spermatids. Hum Reprod 1997;12:336-40.

\section{Reply from Human Fertilisation and Embryology Authority}

Editor-Hewitt et al voice understandable concerns but are misguided. The 1990 Act gives the Human Fertilisation and Embryology Authority jurisdiction over the storage and use of live human gametes and human embryos created in vitro. It requires a patient's written consent to the storage of such gametes or embryos and makes it legally impossible for anyone to give consent to storage of gametes on behalf of another. Thus people with parental responsibility cannot give consent on behalf of a child.

The definition of "gamete" to which the Human Fertilisation and Embryology Authority works is: "A reproductive cell, such as an ovum or a spermatozoon, which has a haploid set of chromosomes and which is able to take part in fertilisation with another of the opposite sex to form a zygote."

On the basis of this definition in conjunction with the five grades of puberty described by Tanner, ${ }^{1}$ the storage of testicular tissue from boys who have reached Tanner stage G2 or beyond requires a licence from the authority. A licence is not required to store testicular tissue from boys who have not reached this stage, and the consent provisions of the 1990 Act do not apply.

A boy under the age of 16 who has reached Tanner stage G2 can give effective consent to the storage of his gametes in accordance with the requirements set out in the 1990 act if he is capable of understanding the nature and possible consequences of the procedures or treatment in accordance with the principles established in the Gillick case. ${ }^{2}$ The doctor in charge of treatment will have to assess whether or not a boy has that competence.

If testicular tissue removed from a boy who has not reached Tanner stage G2 was subsequently developed in vitro so as to create "gametes" within the definition set out above, the storage of that material would require a licence. At that stage, effective consent would have to be given in accordance with the 1990 act

Ruth Deech Chairman

Human Fertilisation and Embryology Authority, London E1 7LS

1 Tanner,JM. Foetus into man:physical growth from conception to maturity.2nd ed. Castlemead, 1989

Gillick v West Norfolk and Wisbech Area Health Authority and DHSS (1996) AC 112.

\section{Refugee doctors face enormous difficulty}

EDITOR-I have been interested by several articles about refugee doctors, ${ }^{12}$ particularly because I started my life in Britain as one. It is hard for people to appreciate fully the mental anguish and physical deprivation, the sense of annihilation and loss of reference points, and the vulnerability and desperation of refugees. Highly educated refugees such as doctors may be more prone than other refugees to concentrate on their mental and spiritual deprivation; this is compounded by repeated disappointments in their attempts to earn their living by their skill and contribute to the society that accepted them.

Although I am a European and prided myself that I had a good knowledge and understanding of European culture and history, the shock of becoming a refugee in a foreign country was overwhelming. The language difficulties, the lack of relatives and friends and knowledge of the "system," the uncertainty and the daily struggle for survival and to keep one's sanity and integrity; all these reduced life to a miserable existence.

I came across most of the official and unofficial refugee organisations. Some were too busy to help; others provided some help and advice, though this was haphazard and understandably, general rather than tailored to a particular group such as refugee doctors. In the medical field I found that the most unhelpful organisation was the overseas division of the General Medical Council. I well understand that the council needs to ensure that those wishing to practise in Britain have at least the same standard of medicine as their British colleagues, but some of its requests were impossible for a refugee to fulfil (for example, to provide my original diploma). Furthermore, when I questioned its practice the division covered up its mistakes, knowing that an individual in a vulnerable position is unlikely to challenge it. However, it learnt that individuals can acquire knowledge of the system and their rights, at which point it rapidly complied with the regulations.
Although I had considerable experience of being disadvantaged and persecuted for political, religious, and ethical convictions, I had no experience of discrimination because of the colour of my skin until I arrived in Britain. In 1987 a black woman in an official position left me in no doubt that she did not believe that a white European in Europe can be a refugee and regarded me as someone who takes opportunities away from non-Europeans.

I must, though, pay tribute to those people in Britain who-through personal encouragement, friendship, and support from their own resources-have made it possible for me and other refugee doctors to be able to contribute to British society.

A Ezsias Senior registrar

John Radcliffe Hospital, Oxford OX3 9DU

1 Eversley J. Refugee doctors in Britain: a wasted resource. BMJ 1997;315:264. (2 August.)

2 Hope B. Refugee doctors forced to do menial jobs. BMJ 1997;315:274. (2 August.)

\section{Correction}

Community based heart health promotion project in England

An editorial error occurred in this letter by Baxter et al (28 February, p 705). The first sentence should read: "Muir et al suggest that the difference in smoking rates between the control and intervention communities after the study period was less than the $6.9 \%$ that we reported because self reporting overestimates quit rates" [not because self reporting underestimates quit rates, as published]

\section{Advice to authors}

We receive more letters than we can publish: we can currently accept only about one third. We prefer short letters that relate to articles published within the past four weeks. We also publish some "out of the blue" letters, which usually relate to matters of public policy.

When deciding which letters to publish we favour originality, assertions supported by data or by citation, and a clear prose style. Letters should have fewer than 400 words (please give a word count) and no more than five references (including one to the BMJ article to which they relate); references should be in the Vancouver style. We welcome pictures.

Letters, whether typed or sent by email, should give each author's current appointment and full address. Letters sent by email should give a telephone and fax number when possible. We encourage you to declare any conflict of interest. Please send a stamped addressed envelope if you would like to know whether your letter has been accepted or rejected.

We may post some letters submitted to us on the world wide web before we decide on publication in the paper version. We will assume that correspondents consent to this unless they specifically say no.

Letters will be edited and may be shortened. 